\title{
Wnt and $\beta$-Catenin Signaling and Skeletal Muscle Myogenesis in Response to Muscle Damage and Resistance Exercise and Training
}

\author{
Dan Newmire \\ Exercise Physiology and Biochemistry Laboratory \\ Department of Kinesiology \\ Texas Woman's University, Denton, Texas, USA \\ 304 Administration Drive, Denton, TX 76204 \\ E-mail: dnewmire@twu.edu \\ Darryn S. Willoughby (Corresponding author) \\ Exercise and Biochemical Nutrition Laboratory \\ Department of Health, Human Performance, and Recreation \\ Baylor University, Waco, Texas, USA \\ 1312 South 5th Street, Waco, TX, USA \\ E-mail: darryn_willoughby@baylor.edu
}

Received: 08-09- 2015

doi:10.7575/aiac.ijkss.v.3n.4p.40
Accepted: 16-10- 2015

Published: 31-10- 2015

URL: http://dx.doi.org/10.7575/aiac.ijkss.v.3n.4p.40

\begin{abstract}
The factors that regulate skeletal muscle hypertrophy in human adults in response to resistance training (RT) has largely focused on endogenous endocrine responses. However, the endocrine response to RT as having an obligatory role in muscle hypertrophy has come under scrutiny, as other mechanisms and pathways seem to also be involved in upregulating muscle protein synthesis (MPS). Skeletal muscle myogenesis is a multifactorial process of tissue growth and repair in response to resistance training is regulated by many factors. As a result, satellite cell-fused myogenesis is a possible factor in skeletal muscle regeneration and hypertrophy in response to RT. The Wnt family ligands interact with various receptors and activate different downstream signaling pathways and have been classified as either canonical ( $\beta$-catenin dependent) or non-canonical ( $\beta$-catenin independent). Wnt is secreted from numerous tissues in a paracrine fashion. The $\mathrm{Wnt} / \beta$-catenin signaling pathway is a highly-regulated and intricate pathway that is essential to skeletal muscle myogenesis. The canonical Wnt/ $\beta$-catenin pathway may influence satellite cells to myogenic commitment, differentiation, and fusion into muscle fibers in response to injury or trauma, self-renewal, and normal basal turnover. The current literature has shown that, in response mechanical overload from acute resistance exercise and chronic resistance training, that the $\mathrm{Wnt} / \beta$-catenin signaling pathway is stimulated which may actuate the process of muscle repair and hypertrophy in response to exercise-induced muscle damage. The purpose of this review is to elaborate on the $\mathrm{Wnt} / \beta$-catenin signaling pathway, the current literature investigating the relationship of the Wnt/ $\beta$ catenin pathway and its effects on myogenesis is response to muscle damage and resistance exercise and training.
\end{abstract}

Keywords: skeletal muscle, hypertrophy, myogenesis, cell signaling, protein synthesis, resistance training

\section{Introduction}

Skeletal muscle accounts for 30-40\% and 40-50 \% of an adult female's and male's body mass, respectively (Fu, Wang, $\& \mathrm{Hu}, 2015)$. Adult, fully-differentiated muscle is considered stable under normal conditions. Perturbations such as age influences a muscle mass loss of $\sim 1.9$ and $1.1 \mathrm{~kg} / \mathrm{dec}$ de, respectively, in men and women (Janssen, Heymsfield, Wang, \& Ross, 2000), and diseases such as cancer cachexia, COPD, and sarcopenia (Agustí et al., 2002; Thomas, 2007) contribute to muscle wasting. In contrast, exercise such as resistance training is known to influence skeletal muscle mass gain (Tesch, 1988). The factors that regulate skeletal muscle hypertrophy in human adults in response to resistance training (RT) has largely focused on endogenous endocrine responses such as testosterone, growth hormone (GH), and insulin growth factor-1 (IGF-1) (Hasani-Ranjbar, Soleymani Far, Heshmat, Rajabi, \& Kosari, 2012; R. R. Kraemer \& Castracane, 2015; W. J. Kraemer, Duncan, \& Volek, 1998; W. J. Kraemer et al., 1999; Madarame, Sasaki, \& Ishii, 2010; Uchida et al., 2009). However, the endocrine response to RT has recently been met with scrutiny as having an obligatory role in muscle hypertrophy due to an observed transient flux and minimized impact on strength and muscle protein synthesis (MPS) outcomes (West, Burd, Staples, \& Phillips, 2010; West \& Phillips, 2010). Similarly, another area largely researched is the anabolic intramuscular signaling of mTORC1, as its constituent up- and down-stream signaling intermediates [e.g., protein kinase A (Akt) and ribosomal protein S6 kinase (p70S6K)] are purported to 
stimulate MPS and protein accretion in response to RT. (Adegoke, Abdullahi, \& Tavajohi-Fini, 2012; Drummond, Dreyer, Fry, Glynn, \& Rasmussen, 2009; Hornberger, Sukhija, \& Chien, 2006; Walker et al., 2011). Furthermore, the associated relationship of cell signaling and MPS has also been met with opposition due to a recent study demonstrating no correlations between the phosphorylation of the signaling proteins measured [Akt, mTORC1, eukaryotic initiation factor $4 \mathrm{E}$ binding protein-1 (4E-BP1), and p60S6K] and changes in muscle volume or lean body mass (LBM). Moreover, measurements of MPS $6 \mathrm{hr}$ following a single bout of resistance exercise were not predictive of muscle hypertrophy following $16 \mathrm{wk}$ of resistance training (Mitchell et al., 2014).

A differing trend of research has focused on observing satellite cell-fused myogenesis as a possible factor in skeletal muscle regeneration and hypertrophy in response to RT. Satellite cells (SC) are mitotically quiescent and reside in a 'stem cell niche' between the basal lamina and the sarcolemma of their associated muscle fibers. SC's become activated into myogenic progenitor cells (MPC's), then proliferate and differentiate into nascent myoblasts, which then fuse to multinucleated myotubes and fuse into existing damaged muscle fibers, thereby donating their myonuclei to promote skeletal muscle repair for self-renewal and/or hypertrophy (Bellamy et al., 2014; Charge \& Rudnicki, 2004; Yin, Price, \& Rudnicki, 2013). It has been suggested that myogenesis is stimulated by Paired box gene 3 and 7 expression (Pax3/7) (Le Grand \& Rudnicki, 2007; Relaix, Rocancourt, Mansouri, \& Buckingham, 2005) and the basic helix-loop-helix family of transcription factors known as the myogenic regulatory factors (MRF's), MyoD, Myf5, myogenin, and MRF4. Both Pax3/7 and MRF's are required for the progression of skeletal myoblasts through the process of myogenesis (Karalaki, Fili, Philippou, \& Koutsilieris, 2009; Le Grand \& Rudnicki, 2007). Once the SC's are activated, they leave their 'niche' and move outside of the basal lamina with the primary function to initiate the cycling and co-expression of Pax7 and MyoD (Le Grand \& Rudnicki, 2007). The intricate process and interactions of both Pax3/7 and MRFs in myogenesis is beyond this article and can be read in depth in other reviews (Bryson-Richardson \& Currie, 2008; Charge \& Rudnicki, 2004; Karalaki et al., 2009; Le Grand \& Rudnicki, 2007; Yin et al., 2013).

Otto, et al (2006) investigated the identity of molecules that may control the development of the satellite cells during embryogenesis and observed that members of the Wnt family of signaling proteins were robust effectors of Pax 7 expression. They concluded that the canonical Wnt signaling pathway and its intracellular response of $\beta$-catenin directly activated satellite cell proliferation by way of translocation to the nucleus resulting in an increase in the expression of Pax7 (Otto et al., 2008; Otto, Schmidt, \& Patel, 2006). The Wnt family proteins are seemingly indispensable regulators of MPC commitment into myoblasts and self-renewal during postnatal myogenesis (Bentzinger, Wang, \& Rudnicki, 2012).

In constructing this mini-review, the online scientific database, PubMed, (www.ncbi.nlm.nih.gov/pubmed) was utilized and studies performed within the past 10 years were primarily utilized. The following sections of this review are to elaborate on the Wnt/ $\beta$-catenin signaling pathway, the current literature investigating the relationship of the Wnt $/ \beta$ catenin pathway, and its effects on myogenesis in response to muscle damage and resistance exercise and training. Re

\section{Wnt and $\beta$-Catenin Signaling and Skeletal Muscle Myogenesis}

\subsection{Wnt/B-catenin Dependent Signaling Pathway}

The wingless-type, mouse mammary tumor virus (MMTV) integration site family (Wnt) signaling ligands are a large family of glycoproteins. These proteins are evolutionarily-conserved secreted cysteine-rich proteins related to the genes Drosophila wingless ( $w g$ ) and mouse Intl (subsequently named Wnt1), and in mammals, most notably humans, there are 19 conserved genes related to the Wnt family. The name 'Wnt' is derived from a combination wingless and Intl genes due to their homology amongst them. The Intl gene was originally identified as an oncogene that became activated by the MMTV and influenced the formation of mammary carcinomas. The Wnt family ligands interact with various receptors and activate different downstream pathways. As shown in Figure 1, these pathways have been classified as either canonical ( $\beta$-catenin dependent) or non-canonical ( $\beta$-catenin independent) signaling pathways. The $\beta$-catenin dependent pathway is activated by a secreted extracellular Wnt ligand that binds to one of seven known transmembrane Frizzled receptors (Fzd), and its co-receptors are known as low-density lipoprotein receptor-related proteins 5 and 6 (LRP5/6)(Baarsma, Konigshoff, \& Gosens, 2013; Brack et al., 2009; Niehrs \& Acebron, 2010; Julia von Maltzahn, Chang, Bentzinger, \& Rudnicki, 2012). Once the Fzd receptor has been activated, it then switches on an intracellular signaling cascade by activating the disheveled proteins (Dvl) and heterotrimeric G-proteins $(\alpha, \beta$ and $\gamma$ subunits), which are required for downstream signaling. In conjunction with the phosphorylation of LRP5/6 proteins, this cascade results in the inactivation of the 'degredation complex' of proteinsm which consists of adenomatosis

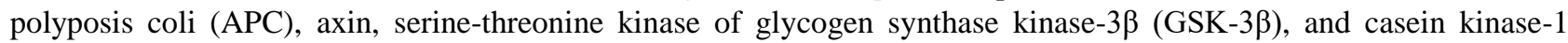
(CK-1) (Li et al., 2012; Tanneberger et al., 2011; Yokoyama, Markova, Wang, \& Malbon, 2012). Inactivation of this complex liberates unphosphorylated $\beta$-catenin to accumulate in the cytosol and sequentially translocate into the nucleus for gene transcription. When Wnt ligand signaling is unavailable, the degradation complex remains activated and the key effector of canonical Wnt signaling of $\beta$-catenin is targeted and phosphorylated by GSK- $3 \beta$ and CK-1 $\alpha$ for proteaosomal degradation by $\beta$-transducin repeat containing E3 ubiquitin protein ligase ( $\beta$-TrCP E3 ligase) and subsequent proteolysis by the ubiquitin-proteasome pathway (Angers \& Moon, 2009; Baarsma et al., 2013; C. Gao, Xiao, \& Hu, 2014; Logan \& Nusse, 2004). However, when $\beta$-catenin has translocated and associates in the nucleus, it functions as a transcriptional co-activator with the T-cell factor/lymphoid enhancer factor-1 (TCF/LEF) family of transcription factors and induces canonical gene transcription to induce Wnt/ $\beta$-catenin target gene expression that modulates numerous biological processes such as myogenesis (Abu-Elmagd et al., 2010; Han, Jin, Seto, \& Yoon, 2011). 


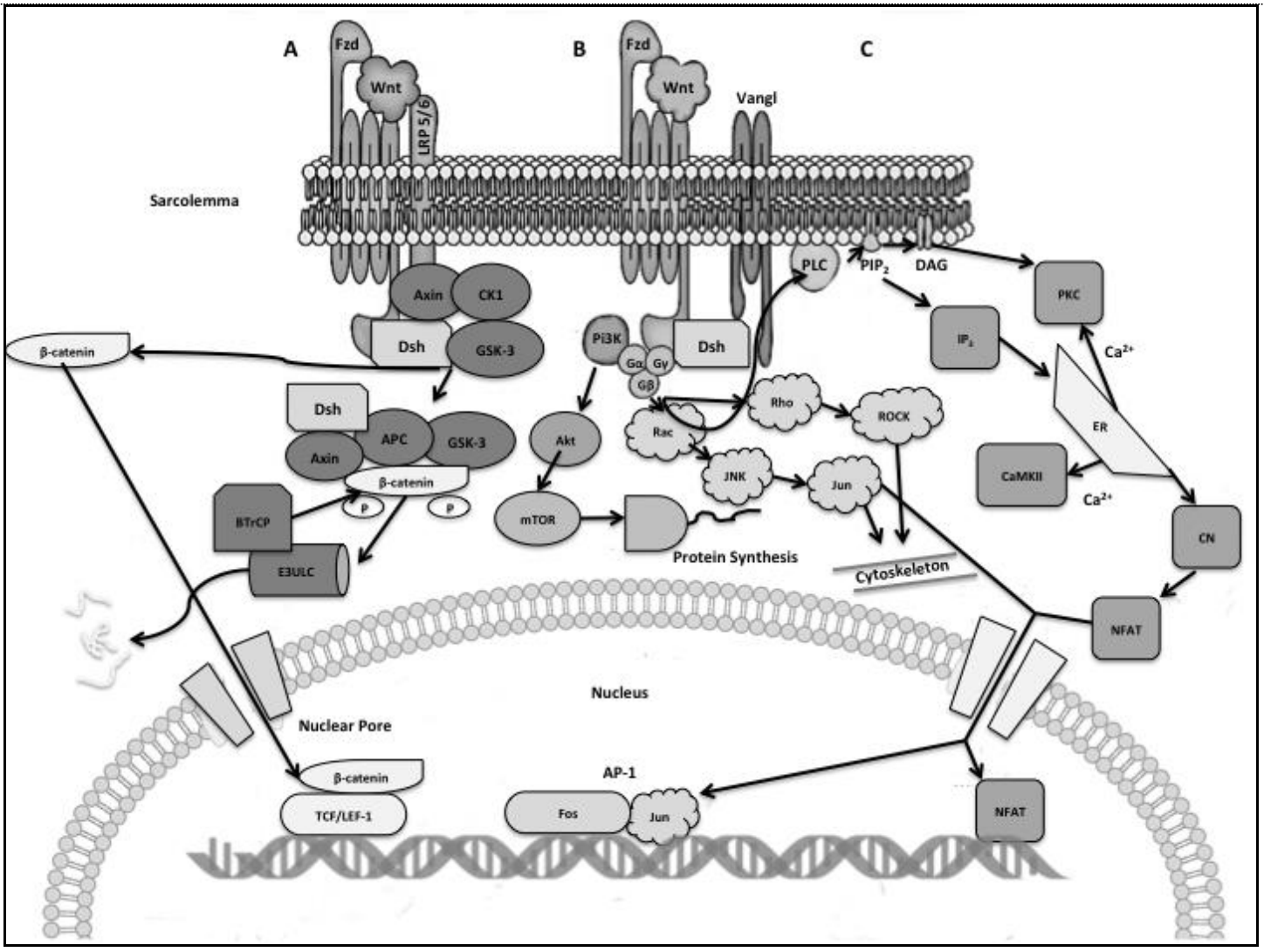

Figure 1. Canonical and Non-Canonical Wnt/ $\beta$-Catenin Signaling Pathways

\section{Canonical}

The Wnt/ $\beta$-catenin signaling pathway consists of adenomatous polyposis coli (APC) and axin which are scaffold proteins that form the $\beta$-catenin degredation complex. Phosphorylation of $\beta$-catenin occurs by the degredation complex kinases, glycogen synthase kinase 3 (GSK-3) and casein kinase $1 \alpha$ (CK-1 $1 \alpha$ ), which form the signal for proteolysis of $\beta$ catenin by a $\beta$-transducin repeat containing E3 ubiquitin protein ligase $(\beta-\operatorname{TrCP} \mathrm{E} 3$ ligase) and then subsequent proteolysis by the ubiquitin-proteasome pathway. Wnt binding activation of the Frizzled (Fzd) and co-receptor lowdensity lipoprotein receptor-related protein 5 (LRP5), G-proteins ( $\alpha, \beta$ and $\gamma$ subunits), and dishevelled (Dvl) proteins are activated and lead to the recruitment of axin to the LRP5 or LRP6. This inhibits the degradation complex, influences the accumulation of $\beta$-catenin translocation to the nucleus and association with transcription factors, lymphoid enhancer factor (LEF) and T-cell factor (TCF), where it acts as a co-activator to actuate transcription.

\section{Non-Canonical}

A) Planar cell polarity (PCP) signaling is independent of $\beta$-catenin and LDL-receptor-related protein (LRP5/6), does not require T-cell factor (TCF) molecules, and leads to the activation of the small RAS homologue gene-family member of GTPases, Rho and Rac. This activates the stress kinase jun N-terminal kinase (JNK) and RHO-associated coiled-coilcontaining protein kinase 1 (ROCK) and leads to cytoskeleton remodeling and changes in cell adhesion and motility. B) Wnt-Calcium $\left(\mathrm{Ca}^{2+}\right)$ signaling is modulated by $\mathrm{G}$ proteins and phospholipases which leads to increases in cytoplasmic free $\mathrm{Ca}^{2+}$ and the activation of protein kinase $\mathrm{C}$ (PKC), calcium calmodulin mediated kinase II (CAMKII), and calcineurin. C) The activation of phospholipase (PLC) by dishevelled (Dvl) leads to the cleavage of phosphatidylinositol-4,5-bisphosphate ( $\mathrm{PIP}_{2}$ ) into inositol trisphosphate (IP3) and diacylglycerol (DAG) and, concurrent with calcium, activates PKC. IP3 binds to membrane receptors and leads to an accumulation of cytoplasmic free $\mathrm{Ca}^{2+}$. This influences an increased gene transcription of activator protein 1 (AP1) and nuclear factor of activated T cells (NFAT). Figure 1 modified from Angers \& Moon, (2009).

\subsection{Wnt Non-Canonical Signaling Pathways}

In contrast to canonical Wnt/ $\beta$-catenin gene transcription there is also a non-canonical signaling pathway that is independent of $\beta$-catenin gene transcription. The signaling event is through Fzd receptors either in conjunction with or independent of LRP co-receptors. The downstream effectors of Wnt signaling have been purported to activate of c-Jun$\mathrm{N}$-terminal kinase (JNK)-dependent or calcium- dependent signaling pathways. Similarly, this non-canonical pathway has also been suggested to activate of PCP (planar-cell-polarity), Ras-related protein 1 (rap1), atypical protein kinase C (aPC), mechanistic target of rapamycin (mTOR), protein kinase A (PKA), and phosphatidylinositide 3-kinase (PI3K) (Baarsma et al., 2013; Gomez-Orte, Saenz-Narciso, Moreno, \& Cabello, 2013; Logan \& Nusse, 2004; Semenov, Habas, Macdonald, \& He, 2007; Yokoyama et al., 2012). The Wnt/PCP signaling influences the regulation of tissue morphogenesis and cell division by way of regulating cellular functions, including cell polarity, cell migration, and 
orientation during development. This pathway modulates and coordinates, in a sequential fashion, the cellular behaviors in a variety of cells (De Calisto, Araya, Marchant, Riaz, \& Mayor, 2005; B. Gao, 2012; Nishita, Endo, \& Minami, 2013; Segalen \& Bellaiche, 2009). Additionally it has been shown, that in differentiated myofibers, Wnt- regulated signaling of Wnt7a binding to the Fzd7 receptor directly activated the Akt/mTOR pathway. The (mechanistic target of rapamycin) mTOR pathway, more specifically mTOR complex 1 (mTORC1), is suggested to be the master regulator of cell growth and proliferation by directly influencing protein synthesis (Laplante \& Sabatini, 2009). Interestingly, the activation of Akt/mTOR occurred independent of IGF-1 receptor activation, which suggests that the non-canonical Wnt pathway may activate muscle protein synthesis (MPS) through mTOR-mediated signaling (J. von Maltzahn, Bentzinger, \& Rudnicki, 2012).

As seen in Table 1, the Wnt family members and components are characterized by the pathway they influence (canonical or non-canonical), the cell type, and the specific receptors that are expressed by the cell (Baarsma et al., 2013). The canonical and non-canonical pathways are considered as separate, thereby having differing actions. However, there are data suggesting cross-talk between pathways by way of Dickkopf (Dkk), a soluble secreted protein that binds to LRP and mediates its internalization. These multifaceted proteins may promote or inhibit certain actions of LRP receptors to influence Wnt/ $\beta$-catenin signaling (van Amerongen \& Nusse, 2009). This interaction suggests that the canonical and non-canonical pathways might be far more interactive than previous thought.

Table 1. The various ligands, receptors, components, and Wnt family members involved in the Wnt signaling pathway

\begin{tabular}{|c|c|}
\hline Components and function & Family members \\
\hline Wnt ligands & $\begin{array}{l}\text { Wnt-1 (Wg), Wnt-2, Wnt-2B, Wnt-3, Wnt-3A, Wnt-4, Wnt- } \\
\text { 5A, Wnt-5B, Wnt-6, Wnt-7A, Wnt-7B, Wnt-8A, } \\
\text { Wnt-8B, Wnt-9A, Wnt-9B, Wnt-10A, Wnt-10B, Wnt-11, } \\
\text { Wnt-16 }\end{array}$ \\
\hline Alternative ligands & Norrin and R-spondin \\
\hline Extracellular modulators & $\begin{array}{l}\text { Secreted Frizzled related proteins (sFRP), Wnt-inhibitory } \\
\text { factor (WIF-1), Dickkopfs (Dkk) }\end{array}$ \\
\hline Fzd receptors & $\begin{array}{l}\text { Fzd1, Fzd2, Fzd3 Fzd4, Fzd5, Fzd6, Fzd7, Fzd8, Fzd9, } \\
\text { Fzd10 }\end{array}$ \\
\hline LRP receptors & $\begin{array}{l}\text { Low-density lipoprotein receptor related proteins } 5 \text { and } 6 \\
\text { (LRP5/6) }\end{array}$ \\
\hline Alternative receptors & Ror2, Ryk and PTK7 \\
\hline Signaling intermediates & Dishevelleds: Dvl1, Dvl2, Dvl3 \\
\hline$\beta$-Catenin destruction complex & $\begin{array}{l}\text { Axin, adenomatosis polyposis coli (APC), glycogen } \\
\text { synthase kinase-3 (GSK-3), casein kinase-1 (CK-1), protein } \\
\text { phosphatases (PP1 and PP2A) }\end{array}$ \\
\hline Cellular trafficking and distribution & Cadherins, pygopus (Pygo) and legless (Lgs/BCL-9) \\
\hline Effector & $\beta$-catenin (Armadillo) \\
\hline Transcription factors & $\begin{array}{l}\text { T-cell factor (TCF-1, TCF-3, TCF-4), lymphoid enhancer } \\
\text { factor (LEF-1) }\end{array}$ \\
\hline Intracellular modulators & $\begin{array}{l}\text { Nemo-like kinase (NLK), Groucho/Transducin-like } \\
\text { enhancer of split (TLE) inhibitor of } \beta \text {-catenin and TCF4 } \\
\text { (ICAT), Chibby (Cby) }\end{array}$ \\
\hline
\end{tabular}

Modified from Baarsma (2013).

\subsection{Wnt Secretion and Distribution}

Wnt proteins are $\sim 40 \mathrm{kDa}$ in size and have been suggested to go through post-translational modification (PTM). These proteins are submitted through a process of glycosylation that plays a role in Wnt folding, secretion, and acylation via lipid modification by a mono-unsaturated fatty acid (palmitoleic acid), which attaches to a conserved serine. The lipid modification is suggested to positively influence Wnt secretory and signaling processes (Hausmann \& Basler, 2006; Mann \& Beachy, 2004; Takada et al., 2006; Willert \& Nusse, 2012; Zhai, Chaturvedi, \& Cumberledge, 2004). This lipid modification has shown to be regulated by an endoplasmic reticulum (ER) protein, porcupine enzyme (Porcn), which is a dedicated and highly-conserved component of the Wnt secretory pathway, and only found in Wnt secreting cells. Porcn, a multi-pass transmembrane O-acyltransferase, is essential for Wnt palmitoylation and maturation. Porcn is also required for serine-dependent acylation for Wnt3a transport from the ER for secretion. This PTM action suggests 
that Wnt proteins require a specific lipid modification for proper intracellular transport during the secretory process (Clevers \& Nusse, 2012; Nusse \& Varmus, 2012; Takada et al., 2006). The next step in the process of intracellular translocation of Wnt ligands is to be carried and released by exosome similar "sorting vesicles" named evenness interrupted (Evi) and Wntless (WLS), which bind to and escort Wnt. Evi/WLS bind to the Wnt protein in the ER, sequentially translocates to the plasma membrane for exocytosis, and then returns to the ER through the Golgi apparatus (Koles et al., 2012; Korkut et al., 2009). Lastly, the intracellular trafficking complex known as the retromer is required for Wnt signaling. The main function of the retromer complex involves the retrograde transport of Wnt translocating carrier proteins, Evi and WLS, back to the Golgi apparatus. It has been proposed that the retromer retrieves endosomal Evi/WLS, which is otherwise targeted and tagged for degradation in lysosomes. This helps with the re-utilization or "recycling" of Wnt transporters. When Evi/WLS are degraded in lysosomes, Wnt secretion becomes impaired (Eaton, 2008; Yu et al., 2014). The impairment of Wnt cell signaling has been found to be significantly detrimental to the growth and development of mammals during embryonic development. In the mouse model, the genetic knockout of numerous Wnt protein and their corresponding Fzd have resulted an early embryonic fatality and deleterious effects on multiple tissues (Julia von Maltzahn et al., 2012). Of these tissues, Wnt has an influence on myogenesis and has been proposed to be a major contributor of skeletal muscle development and regeneration (Bentzinger et al., 2012).

\subsection{Wnt Signaling in Adult Skeletal Muscle Myogenesis}

In contrast to embryonic myogenesis, adult myogenesis is stable under normal conditions with only periodic fusion of satellite cells to compensate for skeletal muscle turnover induced by typical 'daily wear and tear'. Additionally, myofiber tissue regeneration is activated in response to numerous stressors such as weight bearing, exercise-induced muscle damage, stretching, and electrical stimulation (Le Grand \& Rudnicki, 2007; Polesskaya, Seale, \& Rudnicki, 2003). This stress induces myogenic regeneration and requires a template in the process of myogenic regeneration. The extracellular matrix scaffolding at the basal lamina or basement membrane is superior to the sarcolemma, and is pertinent in the regeneration process. SCs are mitotically quiescent $\left(\mathrm{G}_{0}\right.$ phase) and once activated become MPCs and are responsible for muscle regeneration, compensatory hypertrophy, and increasing the myonuclear number during normal adult muscle turnover and growth (Bentzinger et al., 2012; Ciciliot \& Schiaffino, 2010). SCs are largely selfsufficient as a source for muscle regeneration. Collins et al. (2005) transplanted intact myofibers into radiation-ablated muscles and observed a that a very small number of SCs, when associated with one transplanted myofiber, generated over 100 hundred new myofibers which contained thousands of myonuclei. Moreover, these SC's vigorously selfrenewed and re-populated the transplanted muscle (Collins et al., 2005). This dynamic environment coined "stem cell niche" is a process in which adult mammalian skeletal muscle tissue SC's can both replicate themselves for selfrenewing re-population for future needs and/or activate to MPC's and differentiate into myoblasts. These myoblasts then fuse with each other to form multi-nucleated myotubes, which then form into adult muscle fibers and contribute to enhanced myonucleation, as well as the repair of the damaged fibers (Karalaki et al., 2009; Yin et al., 2013).

Stimulating the onset of myogenesis is a multifactorical process. However, it has been shown that Wnt signaling is indispensable in adult myogenesis. Polesskaya, et al. (2003) investigated an adult SC culture model using a hematopoietic restricted cell marker of $\mathrm{CD}_{4} 5^{+}$with both injured and non-injured muscle fibers. Wnts5a and $5 \mathrm{~b}$ genes were expressed in proliferating myogenic cells, but not in differentiated myotubes while Wnt7a was expressed in the myotube. In conjunction, all three Wnt genes expressed were observed to implement myogenic commitment of adult muscle SC regeneration of injured skeletal muscle. Similarly, $\beta$-catenin was highly expressed in this same experiment relative to the uninjured skeletal muscle tissue, which supports the influence of the canonical Wnt pathway as a factor in adult muscle myogenesis (Polesskaya et al., 2003). Additionally, it was found that Wnt4 was influenced by a member of the transforming growth factor beta (TGF- $\beta$ ) superfamily known as myostatin (Mstn), which may act as a specific inhibitor of skeletal muscle growth. Mstn is suggested to inhibit muscle growth by way of down regulating myogenic proliferation and differentiation. However, if Mstn is mutated or inhibited hyper-muscularity is promoted (Grobet et al., 1997; Joulia-Ekaza \& Cabello, 2007; Williams, 2004). Non-canonical Wnt4 has been proposed to stimulate the proliferation of myogenic SC's while inhibiting Mstn signaling, which down-regulates cell proliferation (Steelman, Recknor, Nettleton, \& Reecy, 2006). Jones et al. (2015), using a cell culture model, reported an alternative pathway of Wnt-stimulated myogenesis. They showed that when Wnt3a stimulated the canonical $\beta$-catenin pathway, myogenin became active and, therefore, activated follistatin (FS). FS is also a member of the TGF- $\beta$ family and has a potent inhibitory effect on Mstn and the other TGF- $\beta$ family member, activin A (ActA). Collectively, both Mstn and ActA have been purported to inhibit skeletal muscle myogenic differentiation and skeletal muscle hypertrophy (Gilson et al., 2009; Jones et al., 2015; Wang \& McPherron, 2012). Additionally, it has been proposed that Wnt4 also activates the canonical Wnt/ $\beta$-catenin pathway during myogenic differentiation that has been observed to inhibit the expression of Mstn and the regulating pathways of Mstn (Bernardi et al., 2011; Terada, Misao, Katase, Nishimatsu, \& Nohno, 2013).

\subsection{Canonical Wnt/B-catenin Signaling and Resistance Training}

Skeletal muscle hypertrophy in response to resistance training is a highly- recognized and sought after goal. The process of muscle protein accretion and muscle mass gain is influenced by multiple factors. A more novel area of research is observing how RT influences Wnt signaling and its signaling components on skeletal muscle hypertrophy. Armstrong and Esser (2005) used a synergistic rodent ablation of the plantaris muscle after mechanical overload. The mass differences between day 0 (control) and day 7 demonstrated a $67 \%$ increase in plantaris mass (assessed by muscle wet-weight), and comparatively after 14 days of overload, resulted in a $139 \%$ increase in plantaris mass. They 
attributed this to $\beta$-catenin activation and its down stream components Fzd1, Dvl1, and Lef1. Furthermore, the Wntstimulated $\beta$-catenin/Lef1 targets, c-Myc, Cyclin D1, and Pitx2, were activated during skeletal muscle mechanical overload. Both c-Myc and Cyclin D1 were associated with cell-cycle regulation and in response to muscular hypertrophic growth; both showed increased gene expression in conjunction with muscular overload (Armstrong \& Esser, 2005; Serrano, Baeza-Raja, Perdiguero, Jardi, \& Munoz-Canoves, 2008). Another rodent model that used eccentrically-based downhill running (DHR) on a treadmill, found significant muscle damage in the soleous at 3,5 , and 6 days following the bout of DHR. Furthermore, soleus injury was significantly highest at day 6 compared to day 2 following DHR. Wnt3a, $\beta$-catenin, Lef1, and GSK3 $\beta$ gene and protein expression were measured in the gastrocnemius at the same time points. It was observed that there was no difference in Wnt 3 a nor $\beta$-catenin differences between control groups. However, they did observe a 4.2-fold and 5.0-fold increase in Lef1 mRNA expression and an inhibition of GSK $3 \beta$ at day 5 and 6 , respectively. In response to the proposed outcome that other Wnt family members $5 \mathrm{a}, 5 \mathrm{~b}, 7 \mathrm{a}$, and $7 \mathrm{~b}$ may have had an effect, although unmeasured, the authors felt that Wnt $3 \mathrm{a}$ was the more viable measure based on previous literature in its relation to skeletal muscle repair (Amin et al., 2014). Similarly in another form of muscle tissue unrelated to resistance training, cardiac injury from pressure/volume overload induces a the $\mathrm{Wnt} / \beta$-catenin pathway for cardiac myogenesis. In response to cardiac injury, Wnt $/ \beta$-catenin signaling is suggested to indirectly influence cardiac remodeling, regulation of hypertrophy, and protection of cardiomyocytes from apoptosis (Ozhan \& Weidinger, 2015). A novel topic that deserves much more research and elaboration is the human resistance training model which causes skeletal muscle damage and its relationship with Wnt signaling-induced myogenesis. Leal et al. (2011) reported from an eight-week training study that the intramuscular mRNA expression levels of Wnt1 increased 6.4-fold in response to strength training (ST) and 24.9-fold with power training (PT). There was a significant increase in $\beta$-catenin mRNA expression in response to training, but not between PT and ST groups. Additionally, PT had a 34.1-fold increase in transcription factor Lef1 mRNA expression compared to a 7.3- fold increase from ST. Lastly, Cyclin D1 expression only responded to PT with a 7.7-fold increase compared to control (Leal et al., 2011). Recently, Spillane et al. (2015) investigated a human resistance exercise model that compared a single bout of lowerbody resistance exercises (LB) to a bout of upper- and lower body-resistance exercises (ULB), and observed the responses of serum testosterone concentrations and its effects on muscle testosterone, DHT, androgen receptor (AR) protein content, and AR-DNA binding. More importantly, they additionally determined serum Wnt 4 concentrations and skeletal muscle $\beta$-catenin and the influence that $\mathrm{Wnt} / \beta$-catenin signaling may have on AR-DNA binding. Their results showed no differences in serum free and total testosterone between resistance exercise bouts. Furthermore, intramuscular indices of testosterone and DHT showed no increases at any measured time point. Interestingly, the ULB bout exhibited the greatest increase of serum Wnt 4 at $0.5,1$, and $2 \mathrm{~h}$ following the exercise bout compared to LB, along with a greater total intramuscular $\beta$-catenin elevation at 3 and $24 \mathrm{~h}$ post-exercise. Moreover, they observed an increased in total $\mathrm{AR}$ protein at $3 \mathrm{~h}$ post-exercise for the ULB bout, followed by a diminished amount at $24 \mathrm{hr}$ post-exercise. In addition, AR-DNA binding was increased at both 3 and $24 \mathrm{~h}$ following the ULB bout (Spillane, Schwarz, \& Willoughby, 2015). The authors suggest that, regardless of the response of serum free and total testosterone in LB and ULB resistance exercise bouts, the canonical Wnt4/ $\beta$-catenin signaling may influence the increase in androgen ligand binding to the respective androgen receptors (AR), and the subsequent AR-DNA binding may upregulate the skeletal muscle protein synthetic response. This research corroborates with previous literature using prostate cells suggesting that the AR mediates translocation of Wnt stimulated $\beta$-catenin into the nucleus when exposed to exogenous androgen (Mulholland, Cheng, Reid, Rennie, \& Nelson, 2002).

\section{Conclusion}

Skeletal muscle hypertrophy in response to resistance training is a multifaceted phenomenon that has yet to be fully or consistently elucidated by one singular cell signaling pathway or mechanism. It has been observed that the canonical $\mathrm{Wnt} / \beta$-catenin signaling pathway influences skeletal muscle myogenesis, is indispensable, and highly-critical in skeletal muscle repair and hypertrophy in response to injury or damage. However, it is also apparent that skeletal muscle myogenesis is a multifactorial process that is influenced and regulated by many differing factors. The Wnt/ $\beta$-catenin signaling pathway offers another area of research that may continue to reveal the dynamics of interconnected cell signaling pathway regulating skeletal muscle hypertrophy. Additionally, Wnt may offer a possible plasma biomarker in which to investigate responses to resistance training in various populations. Moreover, $\mathrm{Wnt} / \beta$-catenin signaling may be a crucial biomarker to consider in sarcopenic populations in association with disease and or age in regards to time course and physical activity. However, further research requires further elucidation of Wnt/ $\beta$-catenin signaling on adult human skeletal muscle tissue myogenesis and hypertrophy in conjunction with muscle damaging exercise such as resistance training.

\section{Acknowledgements}

The authors declare no conflicts of interest. 


\section{References}

Abu-Elmagd, M., Robson, L., Sweetman, D., Hadley, J., Francis-West, P., \& Munsterberg, A. (2010). Wnt/Lef1 signaling acts via Pitx2 to regulate somite myogenesis. Developmental Biology, 337(2), 211-219. doi:10.1016/j.ydbio.2009.10.023

Adegoke, O. A., Abdullahi, A., \& Tavajohi-Fini, P. (2012). mTORC1 and the regulation of skeletal muscle anabolism and mass. Applied Physiology, Nutrition, and Metabolism, 37(3), 395-406. doi:10.1139/h2012-009

Agustí, A. G., Sauleda, J., Miralles, C., Gomez, C., Togores, B., Sala, E., . . . Busquets, X. (2002). Skeletal muscle apoptosis and weight loss in chronic obstructive pulmonary disease. American Journal of Respiratory and Critical Care Medicine, 166(4), 485-489.

Amin, H., Vachris, J., Hamilton, A., Steuerwald, N., Howden, R., \& Arthur, S. T. (2014). GSK3beta inhibition and LEF1 upregulation in skeletal muscle following a bout of downhill running. Journal of Physiological Sciences, 64(1), 111. doi:10.1007/s12576-013-0284-5

Angers, S., \& Moon, R. T. (2009). Proximal events in Wnt signal transduction. Nature reviews Molecular cell biology, 10(7), 468-477.

Armstrong, D. D., \& Esser, K. A. (2005). Wnt/beta-catenin signaling activates growth-control genes during overloadinduced skeletal muscle hypertrophy. American Journal of Physiology: Cell Physiology, 289(4), C853-859. doi:10.1152/ajpcell.00093.2005

Baarsma, H. A., Konigshoff, M., \& Gosens, R. (2013). The WNT signaling pathway from ligand secretion to gene transcription: molecular mechanisms and pharmacological targets. Pharmacology \& Therapeutics, 138(1), 66-83. doi:10.1016/j.pharmthera.2013.01.002

Bellamy, L. M., Joanisse, S., Grubb, A., Mitchell, C. J., McKay, B. R., Phillips, S. M., . . Parise, G. (2014). The acute satellite cell response and skeletal muscle hypertrophy following resistance training. PloS One, 9(10), e109739. doi:10.1371/journal.pone.0109739

Bentzinger, C. F., Wang, Y. X., \& Rudnicki, M. A. (2012). Building Muscle: Molecular Regulation of Myogenesis. Cold Spring Harbor Perspectives in Biology, 4(2).

Bernardi, H., Gay, S., Fedon, Y., Vernus, B., Bonnieu, A., \& Bacou, F. (2011). Wnt4 activates the canonical betacatenin pathway and regulates negatively myostatin: functional implication in myogenesis. American Journal of Physiology: Cell Physiology, 300(5), C1122-1138. doi:10.1152/ajpcell.00214.2010

Brack, A. S., Murphy-Seiler, F., Hanifi, J., Deka, J., Eyckerman, S., Keller, C., . . Rando, T. A. (2009). BCL9 is an essential component of canonical Wnt signaling that mediates the differentiation of myogenic progenitors during muscle regeneration. Developmental Biology, 335(1), 93-105. doi:10.1016/j.ydbio.2009.08.014

Bryson-Richardson, R. J., \& Currie, P. D. (2008). The genetics of vertebrate myogenesis. Nature Reviews: Genetics, 9(8), 632-646. doi:10.1038/nrg2369

Charge, S. B., \& Rudnicki, M. A. (2004). Cellular and molecular regulation of muscle regeneration. Physiological Reviews, 84(1), 209-238. doi:10.1152/physrev.00019.2003

Ciciliot, S., \& Schiaffino, S. (2010). Regeneration of mammalian skeletal muscle. Basic mechanisms and clinical $\begin{array}{lllll}\text { implications. Current Pharmaceutical Design, 16(8), 906-914. Retrieved from } & \end{array}$ http://www.ncbi.nlm.nih.gov/pubmed/20041823

Clevers, H., \& Nusse, R. (2012). Wnt/beta-catenin signaling and disease. Cell, 149(6), 1192-1205. doi:10.1016/j.cell.2012.05.012

Collins, C. A., Olsen, I., Zammit, P. S., Heslop, L., Petrie, A., Partridge, T. A., \& Morgan, J. E. (2005). Stem cell function, self-renewal, and behavioral heterogeneity of cells from the adult muscle satellite cell niche. Cell, 122(2), 289301. doi:10.1016/j.cell.2005.05.010

De Calisto, J., Araya, C., Marchant, L., Riaz, C. F., \& Mayor, R. (2005). Essential role of non-canonical Wnt signalling in neural crest migration. Development, 132(11), 2587-2597. doi:10.1242/dev.01857

Drummond, M. J., Dreyer, H. C., Fry, C. S., Glynn, E. L., \& Rasmussen, B. B. (2009). Nutritional and contractile regulation of human skeletal muscle protein synthesis and mTORC1 signaling. J Appl Physiol (1985), 106(4), 13741384. doi:10.1152/japplphysiol.91397.2008

Eaton, S. (2008). Retromer retrieves wntless. Developmental Cell, 14(1), 4-6. doi:10.1016/j.devcel.2007.12.014

$\mathrm{Fu}$, X., Wang, H., \& Hu, P. (2015). Stem cell activation in skeletal muscle regeneration. Cellular and Molecular Life Sciences, 72(9), 1663-1677.

Gao, B. (2012). Wnt regulation of planar cell polarity (PCP). Current Topics in Developmental Biology, 101, $263-295$. doi:10.1016/B978-0-12-394592-1.00008-9

Gao, C., Xiao, G., \& Hu, J. (2014). Regulation of Wnt/ $\beta$-catenin signaling by posttranslational modifications. Cell Biosci, 4(1), 13 
Gilson, H., Schakman, O., Kalista, S., Lause, P., Tsuchida, K., \& Thissen, J. P. (2009). Follistatin induces muscle hypertrophy through satellite cell proliferation and inhibition of both myostatin and activin. American Journal of Physiology: Endocrinology and Metabolism, 297(1), E157-164. doi:10.1152/ajpendo.00193.2009

Gomez-Orte, E., Saenz-Narciso, B., Moreno, S., \& Cabello, J. (2013). Multiple functions of the noncanonical Wnt pathway. Trends in Genetics, 29(9), 545-553. doi:10.1016/j.tig.2013.06.003

Grobet, L., Martin, L. J., Poncelet, D., Pirottin, D., Brouwers, B., Riquet, J., . . Georges, M. (1997). A deletion in the bovine myostatin gene causes the double-muscled phenotype in cattle. Nature Genetics, 17(1), 71-74. doi:10.1038/ng0997-71

Han, X. H., Jin, Y. R., Seto, M., \& Yoon, J. K. (2011). A WNT/beta-catenin signaling activator, R-spondin, plays positive regulatory roles during skeletal myogenesis. Journal of Biological Chemistry, 286(12), 10649-10659. doi:10.1074/jbc.M110.169391

Hasani-Ranjbar, S., Soleymani Far, E., Heshmat, R., Rajabi, H., \& Kosari, H. (2012). Time course responses of serum GH, insulin, IGF-1, IGFBP1, and IGFBP3 concentrations after heavy resistance exercise in trained and untrained men. Endocrine, 41(1), 144-151. doi:10.1007/s12020-011-9537-3

Hausmann, G., \& Basler, K. (2006). Wnt lipid modifications: not as saturated as we thought. Developmental Cell, 11(6), 751-752. doi:10.1016/j.devcel.2006.11.007

Hornberger, T. A., Sukhija, K. B., \& Chien, S. (2006). Regulation of mTOR by mechanically induced signaling events in skeletal muscle. Cell Cycle, 5(13), 1391-1396. Retrieved from http://www.ncbi.nlm.nih.gov/pubmed/16855395

Janssen, I., Heymsfield, S. B., Wang, Z., \& Ross, R. (2000). Skeletal muscle mass and distribution in 468 men and women aged 18-88 yr. Journal of Applied Physiology, 89(1), 81-88.

Jones, A. E., Price, F. D., Le Grand, F., Soleimani, V. D., Dick, S. A., Megeney, L. A., \& Rudnicki, M. A. (2015). $\mathrm{Wnt} / \beta$-catenin controls follistatin signalling to regulate satellite cell myogenic potential. Skelet Muscle, 5(1), 14.

Joulia-Ekaza, D., \& Cabello, G. (2007). The myostatin gene: physiology and pharmacological relevance. Current Opinion in Pharmacology, 7(3), 310-315. doi:10.1016/j.coph.2006.11.011

Karalaki, M., Fili, S., Philippou, A., \& Koutsilieris, M. (2009). Muscle regeneration: cellular and molecular events. In Vivo, 23(5), 779-796. Retrieved from http://www.ncbi.nlm.nih.gov/pubmed/19779115

Koles, K., Nunnari, J., Korkut, C., Barria, R., Brewer, C., Li, Y., . . Budnik, V. (2012). Mechanism of evenness interrupted (Evi)-exosome release at synaptic boutons. Journal of Biological Chemistry, 287(20), 16820-16834. doi:10.1074/jbc.M112.342667

Korkut, C., Ataman, B., Ramachandran, P., Ashley, J., Barria, R., Gherbesi, N., \& Budnik, V. (2009). Trans-synaptic transmission of vesicular Wnt signals through Evi/Wntless. Cell, 139(2), 393-404. doi:10.1016/j.cell.2009.07.051

Kraemer, R. R., \& Castracane, V. D. (2015). Endocrine alterations from concentric vs. eccentric muscle actions: a brief review. Metabolism, 64(2), 190-201. doi:10.1016/j.metabol.2014.10.024

Kraemer, W. J., Duncan, N. D., \& Volek, J. S. (1998). Resistance training and elite athletes: adaptations and program considerations. Journal of Orthopaedic and Sports Physical Therapy, 28(2), 110-119. doi:10.2519/jospt.1998.28.2.110

Kraemer, W. J., Hakkinen, K., Newton, R. U., Nindl, B. C., Volek, J. S., McCormick, M., . . Evans, W. J. (1999). Effects of heavy-resistance training on hormonal response patterns in younger vs. older men. J Appl Physiol (1985), 87(3), 982-992. Retrieved from http://www.ncbi.nlm.nih.gov/pubmed/10484567

Laplante, M., \& Sabatini, D. M. (2009). mTOR signaling at a glance. Journal of Cell Science, 122(20), 3589-3594.

Le Grand, F., \& Rudnicki, M. A. (2007). Skeletal muscle satellite cells and adult myogenesis. Current Opinion in Cell Biology, 19(6), 628-633.

Leal, M. L., Lamas, L., Aoki, M. S., Ugrinowitsch, C., Ramos, M. S., Tricoli, V., \& Moriscot, A. S. (2011). Effect of different resistance-training regimens on the WNT-signaling pathway. European Journal of Applied Physiology, 111(10), 2535-2545. doi:10.1007/s00421-011-1874-7

Li, V. S., Ng, S. S., Boersema, P. J., Low, T. Y., Karthaus, W. R., Gerlach, J. P., . . Clevers, H. (2012). Wnt signaling through inhibition of beta-catenin degradation in an intact Axin1 complex. Cell, 149(6), 1245-1256. doi:10.1016/j.cell.2012.05.002

Logan, C. Y., \& Nusse, R. (2004). The Wnt signaling pathway in development and disease. Annual Review of Cell and Developmental Biology, 20, 781-810. doi:10.1146/annurev.cellbio.20.010403.113126

Madarame, H., Sasaki, K., \& Ishii, N. (2010). Endocrine responses to upper- and lower-limb resistance exercises with blood flow restriction. Acta Physiologica Hungarica, 97(2), 192-200. doi:10.1556/APhysiol.97.2010.2.5

Mann, R. K., \& Beachy, P. A. (2004). Novel lipid modifications of secreted protein signals. Annual Review of Biochemistry, 73, 891-923. doi:10.1146/annurev.biochem.73.011303.073933 
Mitchell, C. J., Churchward-Venne, T. A., Parise, G., Bellamy, L., Baker, S. K., Smith, K., . . Phillips, S. M. (2014). Acute post-exercise myofibrillar protein synthesis is not correlated with resistance training-induced muscle hypertrophy in young men. PloS One, 9(2), e89431.

Mulholland, D. J., Cheng, H., Reid, K., Rennie, P. S., \& Nelson, C. C. (2002). The androgen receptor can promote betacatenin nuclear translocation independently of adenomatous polyposis coli. Journal of Biological Chemistry, 277(20), 17933-17943. doi:10.1074/jbc.M200135200

Niehrs, C., \& Acebron, S. P. (2010). Wnt signaling: multivesicular bodies hold GSK3 captive. Cell, 143(7), 1044-1046. doi:10.1016/j.cell.2010.12.003

Nishita, M., Endo, M., \& Minami, Y. (2013). [Regulation of cellular responses by non-canonical Wnt signaling]. Clinical Calcium, 23(6), 809-815. doi:CliCa1306809815

Nusse, R., \& Varmus, H. (2012). Three decades of Wnts: a personal perspective on how a scientific field developed. EMBO Journal, 31(12), 2670-2684. doi:10.1038/emboj.2012.146

Otto, A., Schmidt, C., Luke, G., Allen, S., Valasek, P., Muntoni, F., . . Patel, K. (2008). Canonical Wnt signalling induces satellite-cell proliferation during adult skeletal muscle regeneration. Journal of Cell Science, $121(\mathrm{Pt} 17)$, 29392950. doi: $10.1242 /$ jcs. 026534

Otto, A., Schmidt, C., \& Patel, K. (2006). Pax3 and Pax7 expression and regulation in the avian embryo. Anatomy and Embryology, 211(4), 293-310. doi:10.1007/s00429-006-0083-3

Ozhan, G., \& Weidinger, G. (2015). Wnt/ß-catenin signaling in heart regeneration. Cell Regen (Lond), 4(1).

Polesskaya, A., Seale, P., \& Rudnicki, M. A. (2003). Wnt signaling induces the myogenic specification of resident CD45+ adult stem cells during muscle regeneration. Cell, 113(7), 841-852. Retrieved from http://www.ncbi.nlm.nih.gov/pubmed/12837243

Relaix, F., Rocancourt, D., Mansouri, A., \& Buckingham, M. (2005). A Pax3/Pax7-dependent population of skeletal muscle progenitor cells. Nature, 435(7044), 948-953.

Segalen, M., \& Bellaiche, Y. (2009). Cell division orientation and planar cell polarity pathways. Seminars in Cell \& Developmental Biology, 20(8), 972-977. doi:10.1016/j.semcdb.2009.03.018

Semenov, M. V., Habas, R., Macdonald, B. T., \& He, X. (2007). SnapShot: Noncanonical Wnt Signaling Pathways. Cell, 131(7), 1378. doi:10.1016/j.cell.2007.12.011

Serrano, A. L., Baeza-Raja, B., Perdiguero, E., Jardi, M., \& Munoz-Canoves, P. (2008). Interleukin-6 is an essential regulator of satellite cell-mediated skeletal muscle hypertrophy. Cell Metab, 7(1), 33-44. doi:10.1016/j.cmet.2007.11.011

Spillane, M., Schwarz, N., \& Willoughby, D. S. (2015). Upper-body resistance exercise augments vastus lateralis androgen receptor-DNA binding and canonical Wnt/beta-catenin signaling compared to lower-body resistance exercise in resistance-trained men without an acute increase in serum testosterone. Steroids, 98, 63-71. doi:10.1016/j.steroids.2015.02.019

Steelman, C. A., Recknor, J. C., Nettleton, D., \& Reecy, J. M. (2006). Transcriptional profiling of myostatin-knockout mice implicates Wnt signaling in postnatal skeletal muscle growth and hypertrophy. FASEB Journal, 20(3), 580-582. doi:10.1096/fj.05-5125fje

Takada, R., Satomi, Y., Kurata, T., Ueno, N., Norioka, S., Kondoh, H., . . Takada, S. (2006). Monounsaturated fatty acid modification of Wnt protein: its role in Wnt secretion. Developmental Cell, 11(6), 791-801. doi:10.1016/j.devcel.2006.10.003

Tanneberger, K., Pfister, A. S., Kriz, V., Bryja, V., Schambony, A., \& Behrens, J. (2011). Structural and functional characterization of the Wnt inhibitor APC membrane recruitment 1 (Amer1). Journal of Biological Chemistry, 286(22), 19204-19214. doi:10.1074/jbc.M111.224881

Terada, K., Misao, S., Katase, N., Nishimatsu, S., \& Nohno, T. (2013). Interaction of Wnt Signaling with BMP/Smad Signaling during the Transition from Cell Proliferation to Myogenic Differentiation in Mouse Myoblast-Derived Cells. International Journal of Cell Biology, 2013, 616294. doi:10.1155/2013/616294

Tesch, P. A. (1988). Skeletal muscle adaptations consequent to long-term heavy resistance exercise. Medicine \& Science in Sports \& Exercise, 20 (5 Suppl), S132-134.

Thomas, D. R. (2007). Loss of skeletal muscle mass in aging: examining the relationship of starvation, sarcopenia and cachexia. Clinical Nutrition, 26(4), 389-399.

Uchida, M. C., Crewther, B. T., Ugrinowitsch, C., Bacurau, R. F., Moriscot, A. S., \& Aoki, M. S. (2009). Hormonal responses to different resistance exercise schemes of similar total volume. Journal of Strength and Conditioning Research, 23(7), 2003-2008. doi:10.1519/JSC.0b013e3181b73bf7

van Amerongen, R., \& Nusse, R. (2009). Towards an integrated view of Wnt signaling in development. Development, 136(19), 3205-3214. 
von Maltzahn, J., Bentzinger, C. F., \& Rudnicki, M. A. (2012). Wnt7a-Fzd7 signalling directly activates the Akt/mTOR anabolic growth pathway in skeletal muscle. Nature Cell Biology, 14(2), 186-191. doi:10.1038/ncb2404

von Maltzahn, J., Chang, N. C., Bentzinger, C. F., \& Rudnicki, M. A. (2012). Wnt signaling in myogenesis. Trends in Cell Biology, 22(11), 602-609.

Walker, D. K., Dickinson, J. M., Timmerman, K. L., Drummond, M. J., Reidy, P. T., Fry, C. S., . . Rasmussen, B. B. (2011). Exercise, amino acids, and aging in the control of human muscle protein synthesis. Medicine \& Science in Sports \& Exercise, 43(12), 2249-2258. doi:10.1249/MSS.0b013e318223b037

Wang, Q., \& McPherron, A. C. (2012). Myostatin inhibition induces muscle fibre hypertrophy prior to satellite cell activation. Journal of Physiology, 590(Pt 9), 2151-2165. doi:10.1113/jphysiol.2011.226001

West, D. W., Burd, N. A., Staples, A. W., \& Phillips, S. M. (2010). Human exercise-mediated skeletal muscle hypertrophy is an intrinsic process. International Journal of Biochemistry and Cell Biology, 42(9), 1371-1375. doi:10.1016/j.biocel.2010.05.012

West, D. W., \& Phillips, S. M. (2010). Anabolic processes in human skeletal muscle: restoring the identities of growth hormone and testosterone. Phys Sportsmed, 38(3), 97-104. doi:10.3810/psm.2010.10.1814

Willert, K., \& Nusse, R. (2012). Wnt proteins. Cold Spring Harbor Perspectives in Biology, 4(9), a007864. doi:10.1101/cshperspect.a007864

Williams, M. S. (2004). Myostatin mutation associated with gross muscle hypertrophy in a child. New England Journal of Medicine, 351(10), 1030-1031; author reply 1030-1031. Retrieved from http://www.ncbi.nlm.nih.gov/pubmed/15352277

Yin, H., Price, F., \& Rudnicki, M. A. (2013). Satellite Cells and the Muscle Stem Cell Niche. Physiological Reviews, 93(1), 23-67.

Yokoyama, N., Markova, N. G., Wang, H. Y., \& Malbon, C. C. (2012). Assembly of Dishevelled 3-based supermolecular complexes via phosphorylation and Axin. J Mol Signal, 7(1), 8. doi:10.1186/1750-2187-7-8

Yu, J., Chia, J., Canning, C. A., Jones, C. M., Bard, F. A., \& Virshup, D. M. (2014). WLS retrograde transport to the endoplasmic reticulum during Wnt secretion. Developmental Cell, 29(3), 277-291. doi:10.1016/j.devcel.2014.03.016

Zhai, L., Chaturvedi, D., \& Cumberledge, S. (2004). Drosophila wnt-1 undergoes a hydrophobic modification and is targeted to lipid rafts, a process that requires porcupine. Journal of Biological Chemistry, 279(32), 33220-33227. doi:10.1074/jbc.M403407200 
